\title{
Effect of TNF- $\alpha$ on the proliferation and osteogenesis of human periodontal mesenchymal stem cells
}

\author{
YITING CAO ${ }^{1,2}$, YIWEI WANG ${ }^{3},{\text { CHENLIN } \text { LI }^{2,4} \text {, QIAN JIANG }}^{2,4^{*}}$ and LAIKUAN ZHU ${ }^{2,5^{*}}$ \\ ${ }^{1}$ Department of Pediatric Dentistry, Ninth People's Hospital, Shanghai Jiao Tong University School of Medicine; \\ ${ }^{2}$ Shanghai Key Laboratory of Stomatology and Shanghai Research Institute of Stomatology, \\ National Clinical Research Center of Stomatology, Shanghai 200011; ${ }^{3}$ Department of Oral Medicine, \\ Huaian Stomatological Hospital, Huai'an, Jiangsu 223300; Departments of ${ }^{4}$ Oral Surgery and \\ ${ }^{5}$ Endodontics and Operative Dentistry, Ninth People's Hospital, Shanghai Jiao Tong University School of Medicine, \\ National Clinical Research Center of Stomatology, Shanghai 200011, P.R. China
}

Received July 13, 2020; Accepted November 24, 2020

DOI: $10.3892 /$ etm.2021.9851

\begin{abstract}
The aim of the present study was to investigate the effect of tumor necrosis factor- $\alpha$ (TNF- $\alpha$ ) on the proliferation and osteogenesis of human periodontal mesenchymal stem cells (hPDLSCs). Antigen expression in hPDLSCs was detected by flow cytometry. hPDLSCs were divided into four groups: A control group with no TNF- $\alpha$ treatment, and three experimental groups treated with $0.1,1$ and $10 \mathrm{ng} / \mathrm{ml}$ TNF- $\alpha$, respectively. The effect of TNF- $\alpha$ on proliferation of hPDLSCs in vitro was detected using a Cell Counting Kit-8 assay. Differentiation into an osteogenic lineage was detected by alkaline phosphatase sand alizarin red staining, and the mRNA and protein expression levels of runt-related transcription factor 2 (Runx2), osteocalcin (OCN) and type I collagen (Col-I) were detected using reverse transcription-quantitative PCR and western blot respectively. Following treatment with $10 \mathrm{ng} / \mathrm{ml} \mathrm{TNF}-\alpha$, proliferation was significantly increased compared with an untreated control group $(\mathrm{P}<0.01)$. Additionally, there was a significant inhibition of alkaline phosphatase enzyme activity, alizarin red mineralization node size, and in the gene and protein
\end{abstract}

Correspondence to: Dr Qian Jiang, Department of Oral Surgery, Ninth People's Hospital, Shanghai Jiao Tong University School of Medicine, National Clinical Research Center of Stomatology, 639 Zhizaoju Road, Shanghai 200011, P.R. China

E-mail: jiangqian0720@hotmail.com

Dr Laikuan Zhu, Department of Endodontics and Operative Dentistry, Ninth People's Hospital, Shanghai Jiao Tong University School of Medicine, National Clinical Research Center of Stomatology, 639 Zhizaoju Road, Shanghai 200011, P.R. China

E-mail: zhulk1997@163.com

${ }^{*}$ Contributed equally

Key words: tumor necrosis factor- $\alpha$, human periodontal mesenchymal stem cell, proliferation, osteogenesis, differentiation expression levels of osteogenic differentiation markers, including Runx2, OCN and COL-I (all, $\mathrm{P}<0.05)$. Taken together, the results indicated that treatment with $10 \mathrm{ng} / \mathrm{ml}$ TNF- $\alpha$ promoted the proliferation of hPDLSCs in vitro and inhibited osteogenic differentiation of hPDLSCs, providing an experimental basis for regulation of hPDLSC-mediated periodontal tissue regeneration.

\section{Introduction}

Periodontal disease is one of the most common oral diseases in adults in China (1). It causes periodontal ligament, cementum and alveolar bone descruction, gingiva, tooth loosening and may leads to the loss of teeth. Previous studies have demonstrated that chronic periodontitis can aggravate or directly affect cardiovascular disease, diabetes, rheumatism, digestive system disease, eye disease and immune function in the body (2-4). The existing periodontal treatment methods include periodontal basic treatment, flap curettage, root planing, application of growth factors $(5,6)$, natural material grafts and guided tissue regeneration (GTR) (7), which can only partially regenerate periodontal tissue. Additionally, the curative effect is not stable. Therefore, it is necessary to elucidate novel and more effective periodontal treatment methods in the clinic (8). Human periodontal mesenchymal stem cells (hPDLSCs) derived from periodontal ligament are a suitable source of stem cells for periodontal tissue regeneration due to the ease of acquisition, simple means of culturing and isolation, multilineage potential and low immunogenicity (9). The release of inflammatory mediators, such as TNF- $\alpha$, not only accelerates the progression of periodontitis, but also affects the regeneration of hPDLSCs (10). It was reported that TNF- $\alpha$ inhibits the osteogenic differentiation of mesenchymal stem cells (MSCs), such as bone marrow stem cells $(11,12)$. However, studies on the effect of TNF- $\alpha$ on the osteogenic ability of hPDLSCs are relatively rare and have provided contradictory results $(13,14)$. Therefore, the aim of the present study was to determine the effect of TNF- $\alpha$ on the proliferation and osteogenic ability of hPDLSCs, providing an experimental basis 
for exploring antagonistic targets of TNF- $\alpha$ and improving the understanding of regeneration and repair of hPDLSCs in periodontitis.

\section{Materials and methods}

Isolation, purification and culture of hPDLSCs. The acquisition and cultivation of hPDLSCs was approved by the Ethics Committee of the Ninth People's Hospital, Shanghai Jiao Tong University School of Medicine (Shanghai, China) and informed consent was provided by the patients in writing. The patients agreed to the use of their teeth for scientific research. A total of 10 teeth were extracted during routine dental care in the Ninth People's Hospital, Shanghai Jiao Tong University School of Medicine were collected from 6 female and 4 male patients. Teeth with no periodontal abnormalities, no inflammation and no caries were obtained from July 2018 to July 2019. The age of the patients ranged from 18-25 years, with a mean age of $20.7 \pm 3$ years. Premolars were washed with PBS three times, and the periodontal ligament tissue from the middle and lower part of the root was scraped, shredded, centrifuged $(400 \mathrm{x} g$ for $5 \mathrm{~min}$ at $37^{\circ} \mathrm{C}$ ), digested with trypsin and placed in $10 \%$ FBS $\alpha$-MEM culture medium (HyClone; Cytiva) containing penicillin-streptomycin, and cultured at $37^{\circ} \mathrm{C}$ with $5 \% \mathrm{CO}_{2}$ in a humidified incubator. The culture medium was changed every 3 days. After the cells reached $\sim 80 \%$ confluence, they were digested with trypsin and sub-cultured at a ratio of 1:3.

Identification of cell surface antigens. Cells were cultured in vitro for three passages, after which they were digested using trypsin-EDTA, and centrifuged at $400 \mathrm{x} \mathrm{g}$ for $5 \mathrm{~min}$ at $37^{\circ} \mathrm{C}$, and the supernatant was removed. The cell suspension was prepared by trypsin digestion and the cell density was adjusted to $1 \times 10^{6} / \mathrm{ml}$. Subsequently, the cell suspension was divided into five $1.5 \mathrm{ml}$ Eppendorf tubes containing the following antibodies: $5 \mu 1$ mouse anti-human STOR-1 (1:1,000; cat. no. ab92395; Abcam), mouse anti-human FITC-CD 90 (1:500; cat. no. BD-561969, BD Pharmingen; BD Biosciences) mouse anti-human FITC-CD34 (1:500; cat. no. BD-555821; BD Pharmingen; BD Bioseciences), mouse anti-human FITC-CD45 (1:500; cat. no. BD-555482; BD Pharmingen; BD Biosciences), and FITC labeled mouse anti-human IgG1 (1:1,000; cat. no. ab99773; Abcam). After incubation for $1 \mathrm{~h}$ at room temperature, the expression of cell surface markers was detected by flow cytometry (Attune NxT; Thermo Fisher Scientific, Inc.) using Invitrogen Attune NxT software version 4.2 (Invitrogen; Thermo Fisher Scientific, Inc.).

Effect of TNF- $\alpha$ on the proliferation of hPDLSCs. A Cell Counting Kit-8 (CCK-8; Dojindo Molecular Technologies, Inc.) assay was used to determine the effect of different concentrations of TNF- $\alpha$ (PeproTech, Inc.) on the proliferation of hPDLSCs. Cell cultures were divided into four groups. Osteogenic induction solution ( $\alpha$-MEM containing $10 \mathrm{mmol} / \mathrm{l}$ dexamethasone, $10 \mathrm{mmol} / 1$ insulin, $0.2 \mathrm{mmol} / 1$ indomethacin and $0.5 \mathrm{mmol} / 13$-isobutyl-1-methylxanthine) was added to the control group without TNF- $\alpha$. The other three experimental groups were treated with osteogenic induction medium containing $0.1 \mathrm{ng} / \mathrm{ml}$ TNF- $\alpha, 1 \mathrm{ng} / \mathrm{ml} \mathrm{TNF}-\alpha$ and $10 \mathrm{ng} / \mathrm{ml}$ TNF- $\alpha$, respectively.
The original culture medium was discarded, cells were washed with PBS three times, digested with trypsin and centrifuged at $400 \mathrm{x} \mathrm{g}$ for $5 \mathrm{~min}$ at $37^{\circ} \mathrm{C}$. The cells were cultured in $100 \mu \mathrm{l}$ medium at a density of $2 \times 10^{4}$ cells/well in a 96 -well plate and cultured at $37^{\circ} \mathrm{C}$ for $24 \mathrm{~h}$. The culture medium was changed every 3 days and cultured continuously for 7 days. On day 7, $10 \mu 1$ of CCK-8 solution was added to each well, and cells were further incubated for $2 \mathrm{~h}$ and gently mixed on a shaker for $5 \mathrm{~min}$ to ensure uniform reagent distribution. The optical density at $450 \mathrm{~nm}$ was measured using a microplate reader. The growth curve was drawn with observation time on the $\mathrm{x}$-axis and the OD value on the y-axis, to analyze and compare cell proliferation.

Effect of TNF- $\alpha$ on osteogenic differentiation of hPDLSCs. Quantitative alkaline phosphatase (ALP) enzyme ELISA kit (cat. no. YM-S2942) and alizarin red staining were used to detect the effect of different concentrations of TNF- $\alpha$ on the osteogenic induction of hPDLSCs. The osteogenic induction solution without TNF- $\alpha$ was added to the control group and the osteogenic induction solution containing $10 \mathrm{ng} / \mathrm{ml} \mathrm{TNF}-\alpha$ was added to the experimental group. After 7 days of induction culture at $37^{\circ} \mathrm{C}$, there was intact cell morphology of spindle or triangular shape in the 96-well plate when observed under a light microscope. The cells were washed using 10\% PBS. A total of $50 \mu \mathrm{l}$ from each well was collected and transferred to another 96-well plate at a density of $1 \times 10^{4}$ cells $/ \mathrm{ml}$. Buffer, substrate and chromogenic solution (provided by the ELISA kit) were added in turn, and the ALP activity of each well was measured at $520 \mathrm{~nm}$.

After osteogenic induction and culture for 21 days as aforementioned, the culture medium was discarded, the cells were fixed with $4 \%$ paraformaldehyde for $10 \mathrm{~min}$ at $4^{\circ} \mathrm{C}$, and stained with alizarin red $\mathrm{S}$ solution for $15 \mathrm{~min}$ at $37^{\circ} \mathrm{C}$. The formation of mineralized nodules was observed under an inverted phase contrast microscope (Olympus Corporation) and imaged.

Reverse transcription-quantitative PCR (RT-qPCR). Total RNA was extracted using TRIzol ${ }^{\circledR}$ (Invitrogen; Thermo Fisher Scientific, Inc.) according to the manufacturer's protocol. Following spectrophotometric quantification using a NanoDrop spectrophotometer (NanoDrop Technologies; Thermo Fisher Scientific, Inc.), $1 \mu \mathrm{g}$ total RNA in a final volume of $20 \mu \mathrm{l}$ was used for RT with a PrimeScript RT Reagent kit (Takara Bio, Inc.) according to the manufacturer's protocol. Aliquots of cDNA were used for mRNA quantification by qPCR using a LightCycler 96 Real-time Quantitative PCR Detection system (Roche Applied Science). The thermocycling conditions were as follows: 35 cycles of denaturation at $94^{\circ} \mathrm{C}$ for $30 \mathrm{sec}$, annealing at $37^{\circ} \mathrm{C}$ for $30 \mathrm{sec}$, and extension at $72^{\circ} \mathrm{C}$ for $1 \mathrm{~min}$. The reaction system $(25 \mu \mathrm{l})$ contained the cDNA, forward and reverse primers, and SYBR-Green PCR MasterMix (Roche Applied Science). Data were analyzed using $\beta$-actin gene expression as the internal standard, and the $2^{-\Delta \Delta \mathrm{Cq}}$ method was used for quantification (15). The sequences of the primers were based on a previous study (16): TNF- $\alpha$ forward, 5'-CCCCTCAGCAAACCACCAAG-3' and reverse, 5'-CTT GGCAGATTGACCTCAGC-3'; $\beta$-actin forward, 5'-CCACAC CCGCCACCAGTTCG-3' and reverse, 5'-CCCATTCCCACC ATCACACC-3'; Runx2 forward, 5'-TGAAATAGGCATCAG 

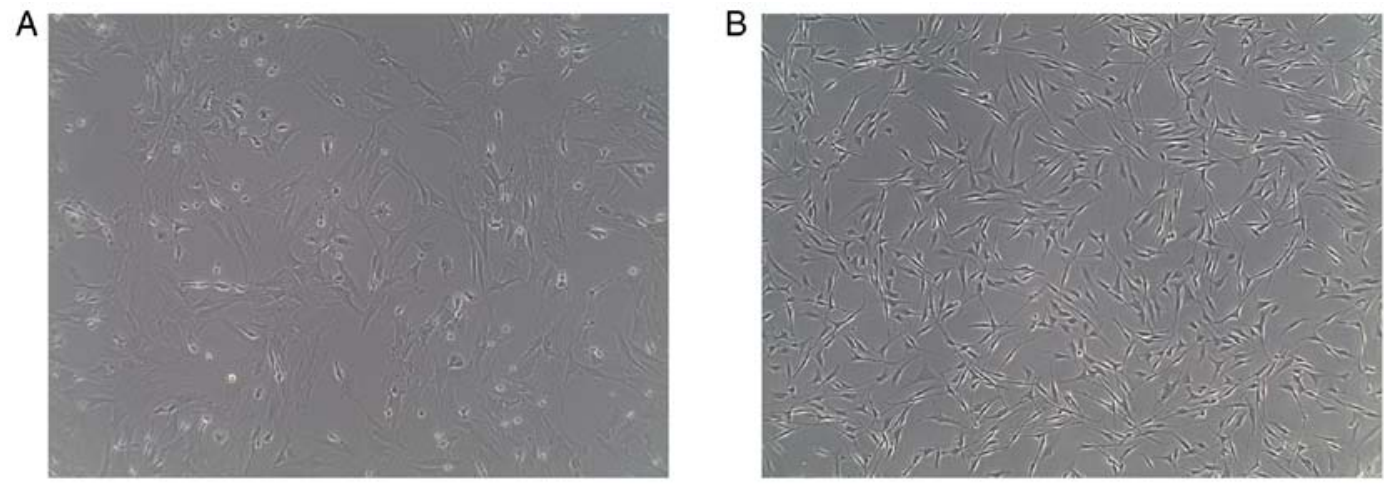

Figure 1. hPDLSC morphology. Morphology of the (A) primary and (B) third-generation hPDLSCs. Magnification, x100. hPDLSCs, human periodontal mesenchymal stem cells.

ACAAA-3' and reverse, 5'-CAGTAGCAAACCGAAACA CT-3'; Col-I forward, 5'-AGTGGTTTGGATGGTGCCAA-3' and reverse, 5'-GCACCATCATTTCCACGAGC-3'; OCN forward, 5'-ATGAGAGCCCTCACACTCCT-3' and reverse, 5'-CTTGGACACAAAGGCTGCAC-3'.

Western blotting. The effect of TNF- $\alpha$ on the expression of osteogenesis-related marker proteins was detected by western blotting. Total proteins were extracted, and the concentration of each protein sample was determined. Cells were harvested and lysed on ice in RIPA Lysis Buffer (Beyotime Institutte of Biotechnology). A bicinchoninic acid assay (Thermo Fisher Scientific, Inc.) was performed to measure the concentration of protein. Equal quantities of protein $(50 \mu \mathrm{g})$ were loaded on an SDS gel, resolved using SDS-PAGE and transferred to a PVDF membrane. Membranes were blocked in 5\% skimmed milk for $2 \mathrm{~h}$. Subsequently the membranes were incubated with primary antibodies against runt-related transcription factor 2 (Runx2), osteocalcin (OCN) and collagen type I $\alpha 1$ (COL-I) and $\beta$-actin (all 1:1,000) overnight at $4^{\circ} \mathrm{C}$. Subsequently, the membranes were washed three times with PBS containing $0.05 \%$ Tween-20 and incubated with a horseradish peroxidase-conjugated secondary antibody $(1: 5,000$; cat. no. sc-2005; Santa Cruz Biotechnology, Inc.) at room temperature for $2 \mathrm{~h}$. The membranes were washed again, and target bands and detected using an enhanced chemiluminescence reagent (Thermo Fisher Scientific, Inc.) and analyzed using ImageJ software v1.8.0 (National Institutes of Health). $\beta$-actin was used as the internal control. The experiments were repeated three times.

Statistical analysis. Data were analyzed using SPSS version 13 (SPPSS, Inc.). Data are presented as the mean \pm standard deviation of three repeats. Differences between two groups were compared using a paired Student's t-test. The significance of differences among more than two groups was assessed using the one-way ANOVA followed by Tukey-Kramer multiple comparisons test. $\mathrm{P}<0.05$ was considered to indicate a statistically significant difference.

\section{Results}

Isolation of hPDLSCs. When the primary hPDLSCs cells were cultured for 3 days, a few cells could be obtained from the tissue block, with an oval and polygonal shape, and of different sizes. The number of the cells began to increase after 5 days, with cells exhibiting a long spindle or polygonal morphology. After 6-8 days of cultivation, occurring prior to osteogenic induction, the number of the cells markedly increased, with the majority of cells exhibiting a long spindle, short spindle or polygonal morphology (Fig. 1A). When the cell confluence rate reached $\sim 80 \%$, they were sub-cultured by selective digestion. The purity and number of the cells after three passages was higher compared with the primary cells, and the growth was considered to be healthy, with no visible abnormalities. The size of the cells was even, they were arranged closely, and predominantly exhibited a long spindle and fiber-like morphology (Fig. 1B).

Evaluation of surface antigens on the hPDLSCs. The expression of surface antigen molecules on hPDLSCs was assessed using flow cytometry (Fig. 2). The results showed that amongst the established markers of MSCs assessed, the proportion of cells expressing STOR-1 was $99.95 \%$, and those expressing CD90 accounted for $99.75 \%$ of the cells. Amongst the markers of blood cell growth, the proportion of cells expressing CD34 was 1.42 and $0.37 \%$ cells were positive for CD 45 . The results of flow cytometry indicated that hPDLSCs cells were successfully isolated and extracted.

Effect of TNF- $\alpha$ on hPDLSCs. The proliferative capacity of third generation hPDLSCs treated with different concentrations of TNF- $\alpha$ was assessed using a CCK-8 assay. The results showed that hPDLSCs exhibited relatively strong proliferative capacity in vitro when compared with the control. On days 1-3, the hPDLSC cells were in linear growth and were proliferating slowly. On days 4-5, cell proliferation was in the logarithmic growth phase, whereas on day 6 , cells entered a stable phase with no apparent proliferation being observed. Compared with the control group, $10 \mathrm{ng} / \mathrm{ml} \mathrm{TNF}-\alpha$ significantly increased the proliferation of hPDLSCs on days 4-5 $(\mathrm{P}<0.001)$, whereas 0.1 and $1 \mathrm{ng} / \mathrm{ml} \mathrm{TNF}-\alpha$ did not have a significant effect on proliferation compared with the control group at any time point (Fig. 3).

Effect of TNF- $\alpha$ on the osteogenic ability of hPDLSCs. Induction of osteogenesis begun on day 7, and the detection of ALP activity showed that in both groups (treated and untreated with TNF- $\alpha$ ), ALP activity gradually increased with cultivation time when 
A

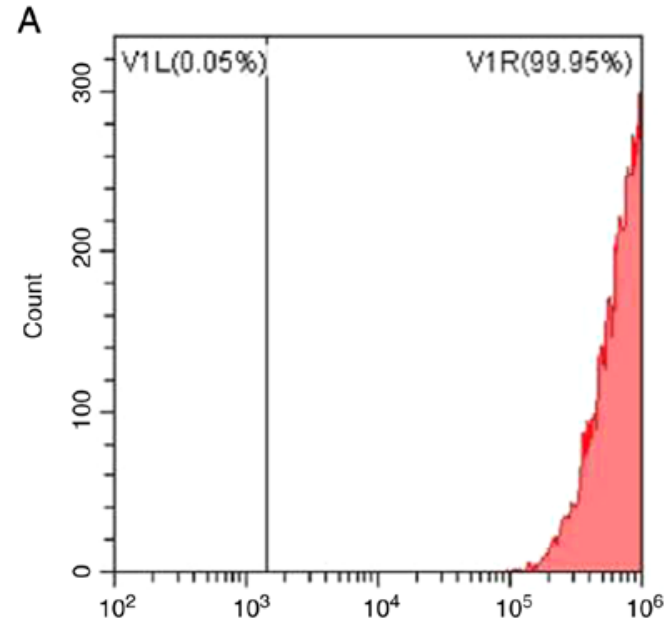

C

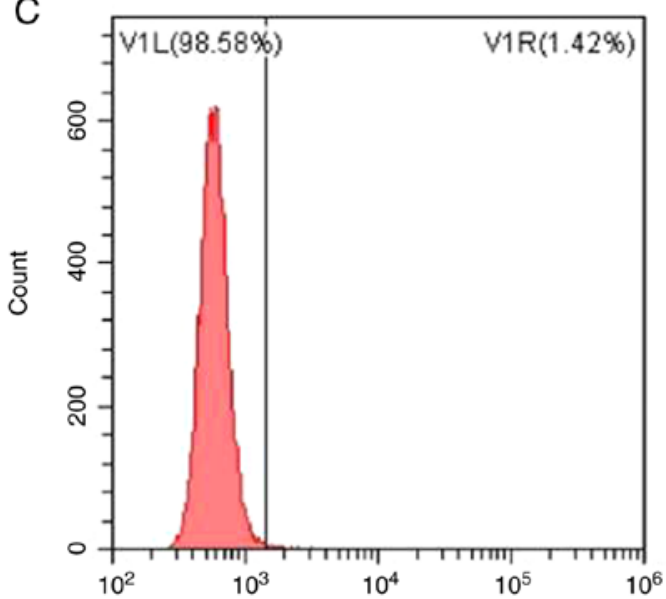

B

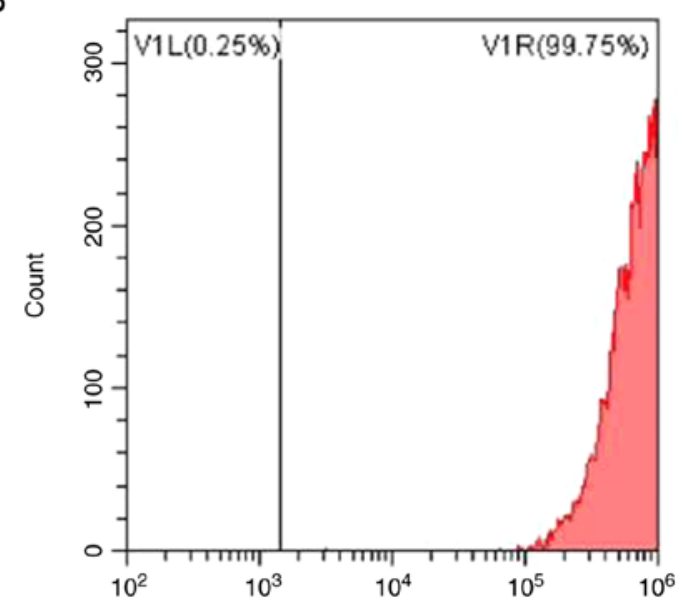

D

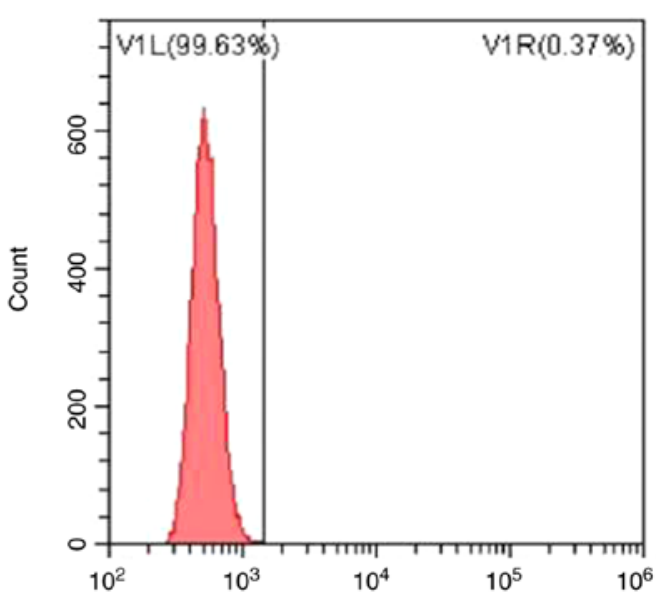

Figure 2. Flow cytometry analysis of surface markers for verification of isolation of human periodontal mesenchymal stem cells. Positive rate of (A) STOR-1, (B) CD90, (C) CD34 and (D) CD45. STOR-1, stromal cell antigen-1; V, volume; L, left; R, right.

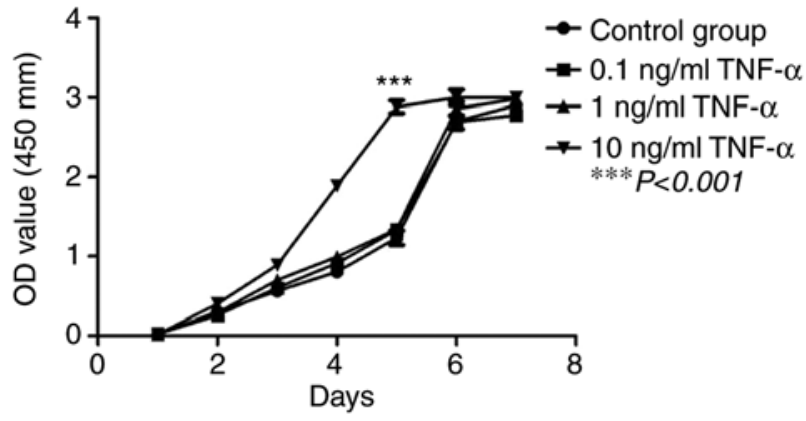

Figure 3. Effects of TNF- $\alpha$ on the proliferation of human periodontal mesenchymal stem cells. ${ }^{* * *} \mathrm{P}<0.001$ vs. the control group. TNF- $\alpha$, tumor necrosis factor- $\alpha$.

compared with the control group, and $10 \mathrm{ng} / \mathrm{ml}$ TNF- $\alpha$ significantly reduced ALP activity (Fig. 4). After 21 days of osteogenesis induction, alizarin red staining showed that compared with the control group, the number and size of red mineralized nodules decreased in the test group $(10 \mathrm{ng} / \mathrm{ml}$ TNF- $\alpha$ ), and the staining was lighter (Fig. 5).

Effect of TNF- $\alpha$ on mRNA and protein expression of osteogenesis-associated genes. Compared with the control group, $10 \mathrm{ng} / \mathrm{ml}$ TNF- $\alpha$ significantly reduced Runx2,
Control group (0 $\mathrm{ng} / \mathrm{ml})$

Experimental group $(10 \mathrm{ng} / \mathrm{ml})$

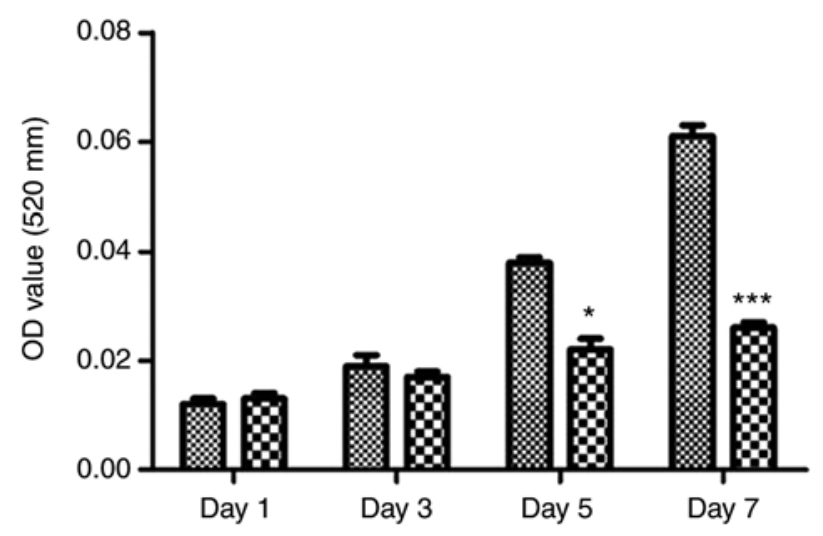

Figure 4. Effects of TNF- $\alpha$ on the ALP activity of human periodontal mesenchymal stem cells. ${ }^{*} \mathrm{P}<0.05$ and ${ }^{* * *} \mathrm{P}<0.001$ vs. the control group. ALP, alkaline phosphatase enzyme.

OCN and COL-I mRNA expression levels ( $\mathrm{P}<0.001$ Fig. 6$)$. Similarly, $10 \mathrm{ng} / \mathrm{ml}$ TNF- $\alpha$ significantly reduced Runx2, OCN and COL-I protein expression levels compared with the control group (all $\mathrm{P}<0.001$; Fig. 7). 

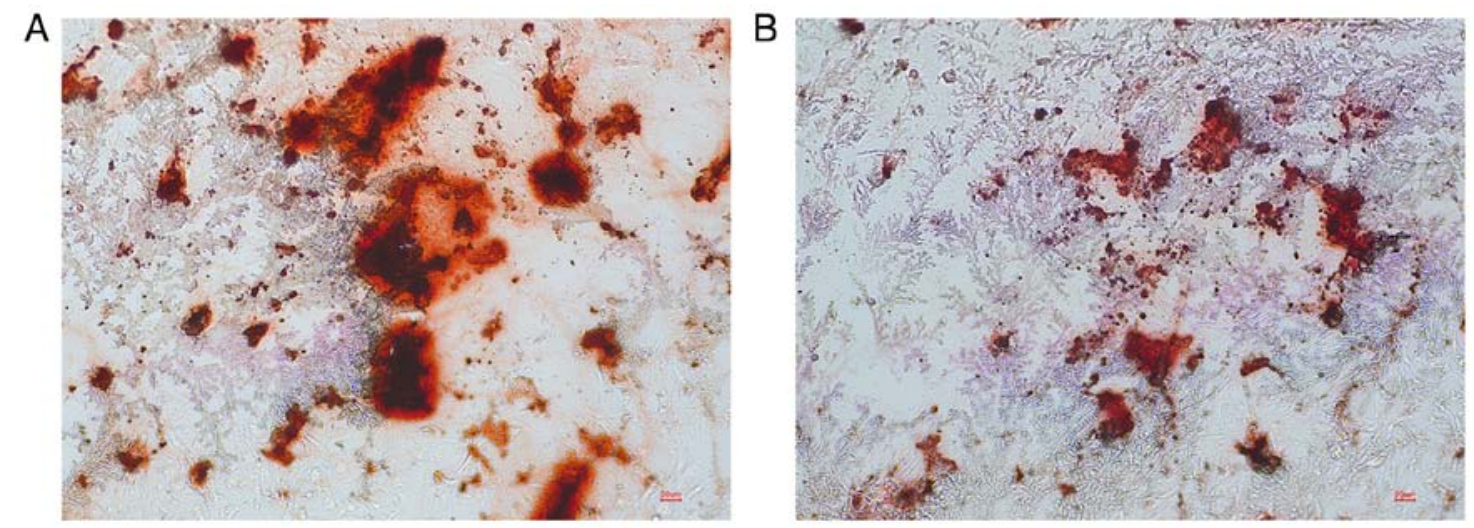

Figure 5. Effects of TNF- $\alpha$ on the alizarin red staining results of human periodontal mesenchymal stem cells. Alizarin red staining of the (A) control group without TNF- $\alpha$ and (B) experimental group treated with $10 \mathrm{ng} / \mathrm{ml}$ TNF- $\alpha$. Magnification, $\mathrm{x} 100$. TNF- $\alpha$, tumor necrosis factor- $\alpha$.
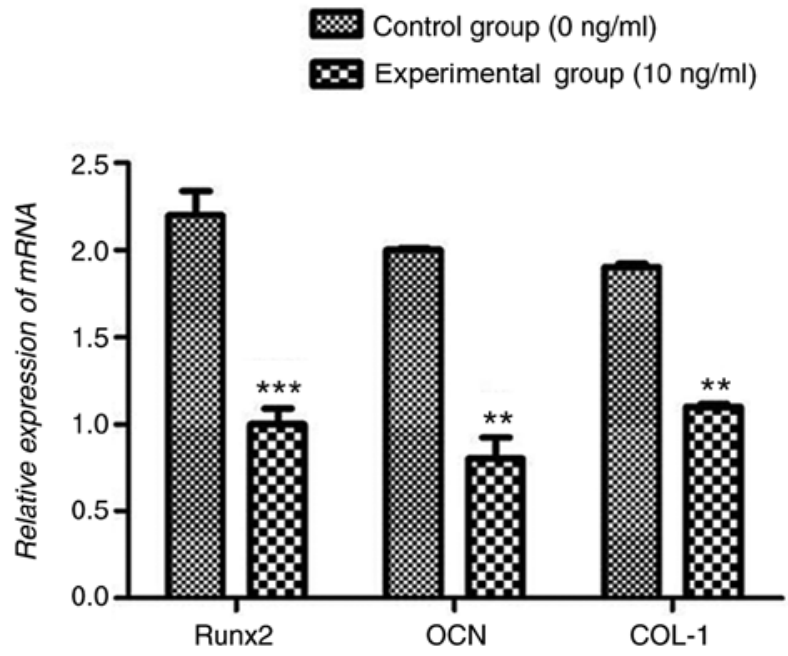

Figure 6. Effects of TNF- $\alpha$ on the mRNA expression of osteogenic genes in human periodontal mesenchymal stem cells. Runx2, OCN and COL-1 expression levels were measured. ${ }^{* *} \mathrm{P}<0.01$ and ${ }^{* * *} \mathrm{P}<0.001$ vs. the control group. TNF- $\alpha$, tumor necrosis factor- $\alpha$; Runx 2 , runt-related transcription factor 2; OCN, osteocalcin; COL-I, collagen type I $\alpha 1$.

\section{Discussion}

Periodontitis can result in swelling of the gums, pain, alveolar bone destruction, occlusal function weakness, tooth loss and/or complete loss of occlusal function, and may thus severely affect a patient's quality of life and health (17). MSCs exhibit self-replication and multi-linage differentiation potential, and are considered a type of adult stem cells that are widely present in human tissues. Under specific conditions, MSCs can differentiate into bone, cartilage, fat, muscle and nerve tissue (18). hPDLSCs are a type of MSCs widely used and studied in periodontal regeneration engineering, and can survive, proliferate and differentiate into cementum, alveolar bone and periodontal ligament-like tissue, and may thus serve as a source of stem cells for periodontal tissue regeneration $(19,20)$. Previous clinical studies have shown that periodontal ligament stem cells were safe and effective in the treatment of periodontal diseases (21).

Enzyme digestion, tissue culture, or a combination of both are commonly used in studies involving acquisition,
A Control group Experimental group

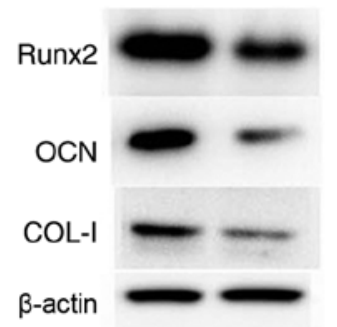

B

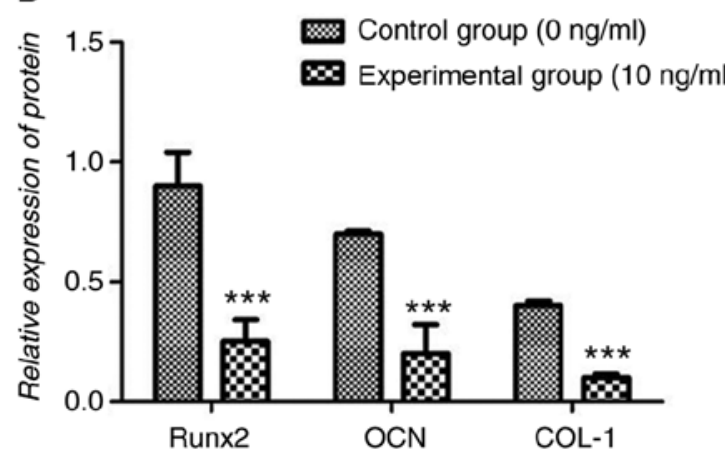

Figure 7. Effects of TNF- $\alpha$ on the protein expression of osteogenic proteins in human periodontal mesenchymal stem cells. (A) Protein expression levels of Runx2, OCN and COL-1. (B) Densitometry analysis of protein expression of Runx2, OCN and COL-1. ${ }^{* * *} \mathrm{P}<0.001$ vs. the control group. TNF- $\alpha$, tumor necrosis factor- $\alpha$; Runx 2 , runt-related transcription factor 2 ; OCN, osteocalcin; COL-I, collagen type I $\alpha 1$.

purification and culture of PDLSCs (22). In the present study, the combined method of enzyme digestion and tissue culture was used to isolate and culture hPDLSCs. This approach was superior to the use of enzyme digestion alone, as it enabled extraction of a greater number of cells and avoided the difficulties in having to adjust the extent of digestion (22). The method used in the current study was also superior to the use of tissue culture alone, which often results in incomplete digestion and low cell survival rates (23). As a result, primary hPDLSCs were obtained and sub-cultured successfully in the present study. At present, to the best of our knowledge, there are no specific identification methods for hPDLSCs. Characteristics of MSCs include high expression of stem cell growth-related proteins, such as antigen molecules including STOR-1, CD105, 
CD90 and CD73; and almost no expression of blood cell growth-related proteins, such as CD34, CD45 and HLA-DR, and these were used to validate whether the cells obtained in the present study were indeed hPDLSCs. After successful sub-culturing of hPDLSCs, the cells were shown to be of a high level of purity, with a high proliferation capacity, with no visible abnormalities, uniform cell size and compact arrangement, exhibiting a long fusiform and fibrous morphology. Flow cytometry was used to confirm the expression of surface antigen molecules, and it was found that the stem cell-related proteins STOR-1 and CD105 were abundantly expressed, whereas expression of the blood cell growth-related proteins CD34 and CD45 were detected at low levels. Together these results provided confidence that the cells extracted and isolated were hPDLSCs.

Periodontitis is a ubiquitous periodontal tissue immune inflammatory disease caused by bacteria (24). The regenerative ability of hPDLSCs is readily affected by the presence of inflammatory mediators such as TNF- $\alpha$, IL-6, IL-11 and IL-17 in the periodontal environment $(25,26)$. Among these, TNF- $\alpha$ is an important member of the TNF family, showing its effect primarily through the NF- $\mathrm{KB}$ or MAPK signaling pathways. It is also the primary inflammatory factor regulating tissue destruction in periodontitis, and is involved in several different inflammatory reactions (27).

In the present study, the effects of different concentrations of TNF- $\alpha$ on the proliferation of hPDLSCs in vitro were compared, and it was found that only $10 \mathrm{ng} / \mathrm{ml} \mathrm{TNF-} \alpha$ could promote the proliferation of hPDLSCs in vitro. It has been previously shown that $10 \mathrm{ng} / \mathrm{ml}$ TNF- $\alpha$ significantly promoted the proliferation of dental pulp stem cells and hPDLSCs (28). In the present study, the effect of TNF- $\alpha$ on cell proliferation was detected using a CCK-8 assay, and the results were consistent with the previous study, where $10 \mathrm{ng} / \mathrm{ml} \mathrm{TNF}-\alpha$ promoted the proliferation of hPDLSCs (28). However, it has also been reported that $10 \mathrm{ng} / \mathrm{ml} \mathrm{TNF-} \alpha$ can significantly induce apoptosis in dental pulp stem cells and hPDLSCs (29). The effect of TNF- $\alpha$ on the proliferation of hPDLSCs in vitro is complex and diverse, and this may be related to the source and method of acquisition of hPDLSCs, culture conditions and detection methods.

ALP, OCN, COL-I and Runx 2 are important factors associated with osteogenesis, and serve important roles in the formation and development of osteocytes, and are thus used as an index to assess the osteogenic induction and differentiation ability of MSCs. Previous studies have shown that TNF- $\alpha$ can inhibit osteoblast bone formation, promote bone resorption, inhibit ALP activity and the mRNA levels of ALP, Runx2 and osterix $(30,31)$. In the present study, $10 \mathrm{ng} / \mathrm{ml} \mathrm{TNF}-\alpha$ was used to inhibit the osteogenic differentiation of normal periodontal ligament stem cells. The decrease in ALP activity and alizarin red staining, and the decreased mRNA and protein expression levels of Runx2, COL-I and OCN showed that $10 \mathrm{ng} / \mathrm{ml} \mathrm{TNF-} \alpha$ could inhibit the osteogenic differentiation of hPDLSCs.

In conclusion, the present study indicated that $10 \mathrm{ng} / \mathrm{ml}$ TNF- $\alpha$ significantly promoted the proliferation of hPDLSCs and inhibited osteogenic differentiation. These results highlight novel potential means of regulating regeneration of hPDLSCs through the use of specific concentrations of inflammatory factors such as TNF- $\alpha$ for the prevention and treatment of periodontitis.

\section{Acknowledgements}

Not applicable.

\section{Funding}

This study was supported by the National Natural Science Foundation of China (grant no. 31800816), and Fundamental Research Program Funding of the Ninth People's Hospital affiliated to Shanghai Jiao Tong University School of Medicine (grant nos. JYZZ109 and JYZZ038).

\section{Availability of data and materials}

The datasets used and/or analyzed during the present study are available from the corresponding author on reasonable request.

\section{Authors' contributions}

QJ and LZ conceived and designed the study. QJ and YC performed the experiments. QJ, YC, YW and CL analyzed the data. YC and CL wrote the manuscript. All authors read and approved the final manuscript. QJ and YC confirm the authenticity of all the raw data. All authors read and approved the final manuscript.

\section{Ethics approval and consent to participate}

The protocols used in the present study were approved by the Ethics Committee of the Ninth People's Hospital, Shanghai Jiao Tong University School of Medicine (Shanghai, China) and informed consent was provided by the patients. The ethics approval reference number is [2018] 376. The patients agreed to the use of their teeth for scientific research.

\section{Patient consent for publication}

All patients provided written informed consent for the publication of their anonymized clinical data.

\section{Competing interests}

The authors declare that they have no competing interests.

\section{References}

1. Cheng ML, Xu MR, Xie YY, Gao XL, Wu HJ, Wang X, Feng XP Tai BJ, Hu DY, Lin HC, et al: Utilisation of oral health services and economic burden of oral diseases in China. Chin J Dent Res 21: 275-284, 2018.

2. Carrizales-Sepúlveda EF, Ordaz-Farías A, Vera-Pineda R and Flores-Ramírez R: Periodontal disease, systemic inflammation and the risk of cardiovascular disease. Heart Lung Circ 27: 1327-1334, 2018.

3. Liccardo D, Cannavo A, Spagnuolo G, Ferrara N, Cittadini A, Rengo $\mathrm{C}$ and Rengo G: Periodontal disease: A risk factor for diabetes and cardiovascular disease. Int J Mol Sci 20: 1414, 2019.

4. Gheorghe ND, Foia L, Toma V, Surdu A, Herascu E, Popescu DM, Surlin P, Vere CC and Rogoveanu I: Hepatitis C infection and periodontal disease: Is there a common immunological link? J Immunol Res 2018: 8720101, 2018. 
5. Panezai J, Ghaffar A, Altamash M, Sundqvist KG, Engström PE and Larsson A: Correlation of serum cytokines, chemokines, growth factors and enzymes with periodontal disease parameters. PLoS One 12: e0188945, 2017.

6. Ravi S, Malaiappan S, Varghese S, Jayakumar ND and Prakasam G: Additive effect of plasma rich in growth factors with guided tissue regeneration in treatment of intrabony defects in patients with chronic periodontitis: A split-mouth randomized controlled clinical trial. J Periodontol 88: 839-845, 2017.

7. Kao RT, Nares S and Reynolds MA: Periodontal regeneration-intrabony defects: A systematic review from the AAP Regeneration Workshop. J Periodontol 86 (Suppl 2): S77-S104, 2015

8. Mlachkova AM and Popova CL: Efficiency of nonsurgical periodontal therapy in moderate chronic periodontitis. Folia Med (Plovdiv) 56: 109-115, 2014.

9. Dave JR and Tomar GB: Dental tissue-derived mesenchymal stem cells: Applications in tissue engineering. Crit Rev Biomed Eng 46: 429-468, 2018.

10. Zheng CX, Chen J, Liu SY and Jin Y: Stem cell-based bone and dental regeneration: A view of microenvironmental modulation. Int J Oral Sci 11: 23-28, 2019.

11. Qin ZJ, Fang ZX, Zhao L, Chen J, Li YT and Liu GY: High dose of TNF- $\alpha$ suppressed osteogenic differentiation of human dental pulp stem cells by activating the $\mathrm{Wnt} / \beta$-catenin signaling. Mol Histol 46: 409-420, 2015.

12. Feng GJ, Shen QJ, Lian M, Gu ZF, Xing J, Lu XH, Huang D, Li LR, Huang S, Wang Y, et al: RAC1 regulate tumor necrosis factor- $\alpha$-mediated impaired osteogenic differentiation of dental pulp stem cells. Dev Growth Differ 57: 497-506, 2015.

13. Jiang C, Wang Q, Song MM, Wang M, Zhao L and Huang Y: Coronarin D affects TNF- $\alpha$ induced proliferation and osteogenic differentiation of human periodontal ligament stem cells. Arch Oral Biol 108: 104519, 2019.

14. Zhao B, Zhang WJ, Xiong YX, Zhang YP, Jia LL and Xu X Rutin protects human periodontal ligament stem cells from TNF- $\alpha$ induced damage to osteogenic differentiation through suppressing mTOR signaling pathway in inflammatory environment. Arch Oral Biol 109: 104584, 2020.

15. Livak KJ and Schmittgen TD: Analysis of relative gene expression data using real-time quantitative PCR and the 2(-Delta Delta C(T)) method. Methods 25: 402-408, 2001.

16. Hwang JH, Chen JC, Yang SY, Wang MF and Chan YC: Expression of tumor necrosis factor- $\alpha$ and interleukin- $1 \beta$ genes in the cochlea and inferior colliculus in salicylate-induced tinnitus. J Neuroinflammation, 8: 30, 2011.

17. Hienz SA, Paliwal S and Ivanovski S: Mechanisms of bone resorption in periodontitis. J Immunol Res 2015: 615486, 2015.

18. Almalki SG and Agrawal DK: Key transcription factors in the differentiation of mesenchymal stem cells. Differentiation 92 $41-51,2016$

19. Ge Y, Li J, Hao Y, Hu Y, Chen D, Wu B and Fang $\mathrm{F}$ : MicroRNA-543 functions as an osteogenesis promoter in human periodontal ligament-derived stem cells by inhibiting transducer of ERBB2. Periodontal Res 53: 832-841, 2018.
20. Corrêa NCR, Kuligovski C, Paschoal ACC, Abud APR, Rebelatto CLK, Leite LMB, Senegaglia AC, Dallagiovanna B and Aguiar AM: Human adipose-derived stem cells (ADSC) and human periodontal ligament stem cells (PDLSC) as cellular substrates of a toxicity prediction assay. Regul Toxicol Pharmacol 9: 75-82, 2018.

21. Su F, Liu SS, Ma JL, Wang DS, E LL and Liu HC: Enhancement of periodontal tissue regeneration by transplantation of osteoprotegerin-engineered periodontal ligament stem cells. Stem Cell Res Ther 6: 22, 2015.

22. Iwasaki K, Komaki M, Yokoyama N, Tanaka Y, Taki A, Kimura Y, Takeda M, Oda S, Izumi Y and Morita I: Periodontal ligament stem cells possess the characteristics of pericytes. J Periodontol 84: 1425-1433, 2013.

23. Wen Y, Yang HX, Wu JJ, Wang A, Chen XD, Hu SJ, Zhang YX, Bai D and Jin ZL: COL4A2 in the tissue-specific extracellular matrix plays important role on osteogenic differentiation of periodontal ligament stem cells. Theranostics 9: 4265-4286, 2019.

24. Bartold PM and Van Dyke TE: An appraisal of the role of specific bacteria in the initial pathogenesis of periodontitis. J Clin Periodontol 46: 6-11, 2019.

25. Misawa MYO, Silvério Ruiz KG, Nociti FH Jr, Albiero ML, Saito MT, Nóbrega Stipp R, Condino-Neto A, Holzhausen M, Palombo $\mathrm{H}$ and Villar CC: Periodontal ligament-derived mesenchymal stem cells modulate neutrophil responses via paracrine mechanisms. J Periodontol 90: 747-755, 2019.

26. Zhao S, Cheng Y and Kim JG: MicroRNA-146a downregulates IL-17 and IL-35 and inhibits proliferation of human periodontal ligament stem cells. J Cell Biochem 120: 13861-13866, 2019.

27. Zhao B, Zhang YP and Xu X: Rutin promotes osteogenic differentiation of periodontal ligament stem cells under inflammatory microenvironment. Shanghai Kou Qiang Yi Xue 28: 356-361, 2019 (In Chinese).

28. Yuan P, Li SH, Zhao L, Yu L, Zhou CM and Wu PL: Biological properties of human periodontal ligament stem cells under inflammatory microenvironment. Chin J Tissue Eng Res 20: 898-905, 2016.

29. Ma Y, Li SH, Ding XX and Wu PL: Effects of tumor necrosis factor- $\alpha$ on osteogenic differentiation and Notch signaling pathway in human periodontal ligament stem cells. Hua Xi Kou Qiang Yi Xue Za Zhi 36: 184-189, 2018 (In Chinese).

30. Jeong BC: ATF3 mediates the inhibitory action of TNF- $\alpha$ on osteoblast differentiation through the JNK signaling pathway. Biochem Biophys Res Commun 499: 696-701, 2018.

31. Sui BD, Hu CH, Liu AQ, Zheng CX, Xuan K and Jin Y: Stem cell-based bone regeneration in diseased microenvironments: Challenges and solutions. Biomaterials 19: 18-30, 2019.

This work is licensed under a Creative Commons Attribution-NonCommercial-NoDerivatives 4.0 International (CC BY-NC-ND 4.0) License. 